\title{
DESPLAZAMIENTO FORZADO INTERNO EN MÉXICO. ASPECTOS LEGALES Y AUSENCIA PRESUPUESTO.
}

\author{
Francisca Silva Hernández* \\ http://orcid.org/0000-0003-3533-0002
}

RECIBIDO: Marzo 2020 / ACEPTADO: Agosto 2020 / PUBLICADO: Septiembre 2020

Como citar: Silva Hernández, Francisca. (2020). Desplazamiento forzado interno en México. Aspectos legales y ausencia presupuesto. Telos: revista de Estudios Interdisciplinarios en Ciencias Sociales, 22 (3), Venezuela. (Pp.626-638).

DOI: www.doi.org/10.36390/telos223.11

\section{RESUMEN}

El Desplazamiento Forzado Interno (DFI) es un fenómeno social, cultural, económico y político complejo en crecimiento a nivel internacional. Las acciones para trabajarlo deben ser de escala global a local. El motivo por el cual se origina es multifactorial. Por ello, este documento tiene como objetivo otorgar un panorama del Desplazamiento Forzado Interno en México con base a dos criterios. El primero, referido al aspecto legal y el segundo, concerniente a la ausencia de asignación de presupuesto en este fenómeno social. Los autores usados como referentes fueron Salazar (2014), Mercado (2016). La metodología utilizada fue cualitativa estructurada en el método, descriptivo, documental y exegético. De este modo, se concluye que aún con la existencia de algunas leyes federales y estatales que prevén la atención parcial de la situación, la carencia normativa y presupuestal específica al DFI hacen prevalecer las condiciones de violaciones $u$ omisiones a derechos fundamentales, humanos y humanitarios.

Palabras Claves: Derechos humanos, movilidad humana, política pública, presupuesto.

Internal forced displacement in Mexico. Legal aspects and absence budget.

\begin{abstract}
Forced Internal Displacement (DFI) is a complex social, cultural, economic and political phenomenon that is growing internationally. The actions to work it must be from global to local scale. The reason for which it originates is multifactorial. Therefore, this document aims to provide an overview of Forced Internal Displacement in Mexico based on two criteria. The first, referring to the legal aspect and the second, concerning the absence of a budget in this social

\footnotetext{
* Doctora en Métodos de Solución de Conflictos y Derechos Humanos. Profesora Tiempo Completo en Universidad Juárez Autónoma de Tabasco (México). Miembro del Sistema Nacional de Investigadores. Correo electrónico fany987@hotmail.com
} 
phenomenon. The authors used as referents were Salazar (2014), Mercado (2016). The methodology used was qualitative, structured in the method, descriptive, documentary and exegetical. In this way, it is concluded that even with the existence of some federal and state laws that provide partial attention to the situation, the specific regulatory and budgetary absence of the DFI makes the conditions of violations or omissions of fundamental, human and humanitarian rights prevail.

Keywords: Human rights, human mobility, public policy, budget.

\section{Introducción}

La movilidad humana representa a nivel mundial un fenómeno social dinámico que otorga una visibilidad de hechos sociales, derivado de ello, el DFI simboliza un problema social en crecimiento, del cual se debe ejecutar acciones concretas desde cada país que garantice el derecho de libre circulación en sus diferentes concepciones tales como trata de personas, migrantes, refugiados, desplazamiento forzado; por motivos económicos, laborales, familiares, violencia, desastres naturales, entre otros. Por ello, es importante analizar el marco legal que garantice los derechos humanos universales, que el Estado a través de sus instituciones otorgue el acceso a los mismos respetando y acatando el marco legal de su competencia aplicando el convencionalismo mediante los instrumentos internacionales que velan por estos derechos.

En el Informe del Relator Especial sobre los derechos humanos de los desplazados internos (Naciones Unidas, 2016), la estadística a nivel mundial ascendió históricamente de 59,5 millones de desplazados forzosos en 2014, frente a 51,2 millones el año anterior y 37,5 millones diez años antes; distinguiendo a nivel mundial que 1 de cada 122 individuos es refugiado, desplazado interno o solicitante de asilo.

En 2018, de los 28 millones de nuevos desplazados, 10,8 millones correspondieron a víctimas por conflictos de violencia (criminal, política, comunitaria, armado) y 17,2 millones de desplazados se atañen a desastres (relacionados con el clima y geofísicos) (Observatorio de Desplazamiento Interno-IDMC, 2019).

En México, a través del Informe Especial sobre Desplazamiento Forzado Interno-DFI México (Comisión Nacional de Derechos Humanos, 2016), se detectaron 35,433 personas víctimas de manera referenciada, ya sea por servidores públicos, por las propias víctimas desplazadas o por personas que no eran víctimas. Autoridades estatales y municipales (incluidos los OPDH) identificaron la presencia de 37,062 víctimas entre los años 2013 a 2015 en sus respectivos territorios. En caso particular alrededor de 4,554 personas (1,177 familias) en el estado de Sinaloa, identificadas en un expediente de queja en el año 2016 que integró la Comisión Nacional de Derechos Humanos-CNDH (2016); respecto a grupos vulnerables se registró 16,092 personas indígenas desplazadas (5,364 familias) atendidas por la Comisión Nacional para el Desarrollo de los Pueblos Indígenas entre 2006 y 2013.

Para el año 2018, de acuerdo a Pérez Vázquez, et al (2019), el DFI ocurrió en los Estados siguientes: 
Tabla 1. Casos de DFI en México.

\begin{tabular}{|l|c|c|}
\hline \multicolumn{1}{|c|}{ Estados } & Motivo de DFI & $\begin{array}{c}\text { Número de } \\
\text { personas } \\
\text { desplazadas }\end{array}$ \\
\hline Guerrero & Violencia por grupos armados organizados & 5056 \\
\hline Chiapas & Conflictos territoriales, conflicto social, violencia política & 5035 \\
\hline Sinaloa & Violencia por grupos armados organizados & 860 \\
\hline Oaxaca & Conflictos territoriales, conflicto social, violencia política & 300 \\
\hline Michoacán & Violencia por grupos armados organizados & 240 \\
\hline
\end{tabular}

Fuente: Elaborado por el autor con base al Informe Episodios de Desplazamiento Interno Forzado Masivo en México (Pérez Vázquez et al, 2019)

El Informe distingue que de forma directa no se evidencia el DFI por proyectos extractivos mineros, sin embargo, se expone que en el caso del estado de Guerrero los DFI puedan tener un fin oculto de proyectos extractivos. Sin duda, el escenario de alcance y pertinencia a este fenómeno social debe ser con la formación transdisciplinar y multidisciplinar de profesionales a través de redes de colaboración académica y científica que otorguen un diagnóstico e informe integral de la situación actual y predominante antes, durante y a posteriori del DFI, con el objetivo de ir enmarcando las acciones de políticas públicas por atender con base a prioridades y regiones del estado mexicano.

Por tanto, se considera pertinente otorgar un panorama del DFI en México con base a dos criterios. El primero, referido al aspecto legal y el segundo, concerniente a la ausencia de presupuesto en este fenómeno social que repercuten en los derechos civiles, humanos y políticos de personas en movilidad humana.

Para la comprensión de esta problemática este documento está basado en una metodología cualitativa (Garza, 2013), estructurada desde el método documental el cual ocupó una revisión bibliohemerográfica que otorgó los conceptos doctrinales e informes, así como distinguir los elementos y características respecto al DFI a partir de los derechos humanos y el derecho humanitario.

Se utilizó el método exegético como el proceso de interpretación y estudio de textos legales y regulación de los mismos (Villabella, 2009), abordando la norma con perspectivas del "discurso del objeto" o "discurso conceptista", es decir, la objetividad de la realidad sobre la que se pronuncia a partir de términos, conceptos y definiciones.

Para su interpretación Luhmann (2006), refiere que no puede observarse a la sociedad desde lo externo debido a que la dinámica está en función de la misma, lo que conlleva a comprenderla desde su incidencia.

EI DFI representa para México ausencia de Ley que aborde en el marco jurídico este escenario mediante instituciones garantes del acceso a la seguridad de la persona. Solamente se enuncia en la Ley General de Educación (Cámara de Diputados del H. Congreso de la Unión, 2019); Ley de Asistencia Social (Cámara de Diputados del H. Congreso de la Unión, 2004), y Ley General de Víctima (Cámara de Diputados del H. Congreso de la Unión, 2013). Periodo en el que se eleva a rango constitucional en México los derechos humanos, teniendo una última reforma constitucional en 2017, con atención a mecanismos de reparación de daños, reconocimiento a grupos vulnerables, derechos de ayuda, asistencia y atención, medidas de 
apoyo inmediato, en materia de alojamiento y alimentación; traslado; protección; materia jurídica; reparación integral; así como la creación del sistema de atención a víctimas.

En ese contexto, este artículo describe en un primer acápite el DFI en un tejido legalnormativo de instrumentos internacionales, así como los existentes en el estado mexicano; en un segundo apartado el reconocimiento y vinculación de los derechos humanos violados u omitidos en el DFI y como un último acápite lo competente al presupuesto en cuanto a la ausencia del mismo a esta problemática social derivada de la movilidad humana.

\section{Desplazamiento forzado interno en el plano legal.}

La Declaración de Cartagena sobre Refugiados (Alto Comisionado de las Naciones Unidas para los Refugiados, 1984), es el primer documento a nivel internacional que reconoce a las personas en DFI, manifestándolo como preocupante en el que las autoridades nacionales e internacionales competentes deben ofrecer la protección y asistencia a los desplazados.

De acuerdo a la Conferencia Internacional sobre Refugiados Centroamericanos (CIREFCA, 1989), personas desplazadas son aquellas obligadas a desertar sus hogares 0 actividades económicas usuales debido a que su vida, seguridad o libertad son amenazadas por la violencia generalizada o el conflicto prevaleciente. Como acto particular de salvaguardar su seguridad la movilidad se suscita de forma interna en su país.

Naciones Unidas (1998, p. 5), define como desplazados internos a:

"personas o grupos forzados u obligados a escapar, huir de su hogar, lugar de vivienda habitual, como mecanismo preventivo o de resultado por violencia, conflicto armado, transgresión a los derechos humanos 0 desastres/catástrofes naturales provocados por el ser humano, delimitando que no han cruzado una frontera estatal internacionalmente reconocida"

Este concepto adhiere a los desplazados en los que se ejerce acción de coacción revestida de forma de escape o huida del espacio en el que debe tener su pleno desarrollo en condiciones de vida digna (hábitat), con el objeto de evadir actos que los expongan en un estado de peligro, zozobra, inseguridad, vulnerabilidad y/o riesgo.

Los desplazados internos "IDP" por el acrónimo en inglés de "Internally Displaced People", son aquellos que permanecen por diversas razones que sean, al interior de su país. Para Mestries (2018), el DFI ya no es sólo derivado por acciones de violencia, en el caso de México, se adhieren los originados por cuestiones ambientales.

La Comisión Mexicana de Defensa y Promoción de los Derechos Humanos-CMDPDH (2019), comprende de forma singular a las víctimas de DFI teniendo como base principal la violación a los derechos humanos, identifica a las víctimas como aquellas que desertan de su domicilio habitual hacia otra colonia de su mismo municipio, hacia otro municipio de su estado 0 hacia otro estado del país.

El marco legal que encuadra el DFI en la esfera internacional son los instrumentos internacionales de la Declaración Universal de los Derechos Humanos (Naciones Unidas, 1948), Declaración Americana de los Derechos y Deberes del Hombre (Organización de los Estados Americanos-OEA, 1948), Convenios de Ginebra (Comité Internacional de la Cruz Roja, 1949), Declaración de San José sobre Refugiados y Personas Desplazadas y los Principios Rectores 
de los Desplazamientos Internos (ACNUR, 1994), Convenio 169 (Organización Internacional del Trabajo-OIT, 1989).

El año 2019 para México resulta trascendental en el tema de DFI, toda vez que se crea el escenario para debatir la propuesta de Ley en dicha materia; teniendo como objeto prevenir, investigar, sancionar y reparar el desplazamiento forzado interno. Es así que trata de concebirse como una Ley que vaya previendo, atendiendo, otorgando una acción de sanción y reparación integral del daño ante la vulnerabilidad, riesgo, violación de derechos de las personas.

La Convención de Kampala (Unión Africana, 2009), planteó que "Los Estados deberán proteger del desplazamiento a comunidades con apego y dependencia a la tierra por razón de cultura y valores espirituales (cosmovisión), haciendo la excepción por imperiosas y convincentes razones de interés público."

En el caso de México, además de adherirse al artículo primero Constitucional por cuestiones de instrumentos internacionales es importante vincularlo con el artículo dos Constitucional, el cual se aboca a los derechos de los pueblos y comunidades indígenas; asimismo, tener previsto el artículo cuarto, once y veintisiete Constitucional (Cámara de Diputados del H. Congreso de la Unión, 1917), estos últimos artículos en atención a que el DFI se puede originar por aquellas actividades de "desarrollo" de empresas multinacionales, empresas privadas, cuestiones militares, extractivismo, megaproyectos.

El marco normativo con el que cuenta el estado mexicano en tema de movilidad humana es la Ley de Migración (Cámara de Diputados del H. Congreso de la Unión, 2011a), Ley sobre Refugiados, Protección Complementaria y Asilo Político (Cámara de Diputados del H. Congreso de la Unión, 2011b), y la Ley General de Población (Cámara de Diputados del H. Congreso de la Unión, 1974) las cuales no tienen en consideración a las DFI.

A contrario sensu, en la legislación mexicana existen leyes que, si bien no son relativos a la movilidad humana, la abordan de forma específica asumiendo responsabilidades de atención a víctimas de DFI; mismas que a continuación se abordan:

Ley General de Educación (Cámara de Diputados del H. Congreso de la Unión, 2019) su artículo nueve, fracción $\mathrm{Xl}$, establece que toda autoridad educativa en el ámbito de su competencia y con la finalidad de implantar criterios de ejercicio pleno del derecho a la educación de forma equitativa y de excelencia, debe promover medidas para facilitar y garantizar la incorporación y permanencia a servicios educativos a niñas, niños, adolescentes y jóvenes que enfrenten DFI. Es decir, este derecho en ningún momento puede ser restrictivo, al contrario, se deben crear las condiciones óptimas.

Ley de Asistencia Social (Cámara de Diputados del H. Congreso de la Unión, 2004), en su artículo cuatro dispone que tiene "derecho a la asistencia social individuos y familias que, por condiciones físicas, mentales, jurídicas, económicas o sociales, requieran de servicios especializados para su protección y su plena integración al bienestar". En esta misma Ley expresa que el Sistema Nacional para el Desarrollo Integral de la Familia, tiene como función prestar servicios de representación y asistencia jurídica, así como orientación social que por distintas circunstancias no puedan ejercer plenamente sus derechos a personas con ciertas características entre ellos, indígenas desplazados.

Respecto a la Ley General de Víctimas (Cámara de Diputados del H. Congreso de la Unión, 2013), obliga a las autoridades de todos los ámbitos gubernamentales a actuar conforme principios y criterios establecidos en la misma, así como brindar atención inmediata en especial en materias de salud, educación y asistencia social, en caso contrario quedarán sujetos a las 
responsabilidades administrativas, civiles o penales a que haya lugar. Es decir, la competencia de violación u omisión de los derechos de las personas ante tal situación por parte de las autoridades y propios ciudadanos, puede acarrear responsabilidades a través de las tres vías antes citadas.

En esta Ley se considera la reparación integral, como aquella que comprende las medidas de restitución, rehabilitación, compensación, satisfacción y garantías de no repetición, en sus dimensiones individual, colectiva, material, moral y simbólica. Cada una de estas medidas debe ser implementada a favor de la víctima teniendo en cuenta la gravedad y magnitud del hecho victimizante cometido o la gravedad y magnitud de la violación de sus derechos, así como las circunstancias y características del hecho victimizante. Es decir, la reparación va adherida a un proceso de trabajo de resiliencia y resignificación de la dignidad humana y vida digna de toda persona (Salazar y Álvarez, 2018).

Bajo el principio de "enfoque diferencial y especializado" (Cámara de Diputados del $\mathrm{H}$. Congreso de la Unión, 2013) prevé el reconocimiento de grupos en mayor grado de vulnerabilidad, siendo así que las autoridades deben aplicar la ley, garantías especiales y medidas de protección a grupos expuestos a un mayor riesgo de violación a sus derechos, dentro de este grupo están previstos aquellas personas en situación de desplazamiento interno.

Como parte de los derechos de ayuda, asistencia y atención a las personas de desplazamiento forzado interno, deben recibir ayuda médica y psicológica especializada de emergencia (Cámara de Diputados del H. Congreso de la Unión, 2013). Asimismo, las acciones de reparación del daño causado a las víctimas no sólo tangibles sino también de forma intangible deben considerarse el apego estricto a los derechos humanos y justicia.

A nivel estatal en México las entidades que tienen una Ley al respecto, son los siguientes; el antes Distrito Federal hoy Ciudad de México con la "Ley de Interculturalidad, atención a Migrantes y Movilidad Humana en el Distrito Federal" (Asamblea Legislativa del Distrito Federal V Legislatura, 2011). El estado de Chiapas a través de la "Ley para la prevención y atención del desplazamiento interno en el estado de Chiapas" (Congreso del Estado Libre y Soberano de Chiapas, 2012).

El estado de Guerrero mediante la "Ley número 487 para prevenir y atender el desplazamiento interno en el estado de Guerrero" (H. Congreso Local, 2014). El estado de Morelos si bien no tiene una Ley específica si contempla a los DFI en la "Ley de atención y reparación a víctimas del delito y de violaciones a los derechos humanos para el estado de Morelos" (H. Congreso del Estado, 2013a), está entidad en su Ley de Víctimas del estado de Morelos ( $\mathrm{H}$. Congreso del Estado, 2013b), reconoce el desplazamiento interno como la consecuencia de hechos victimizantes, a quienes deberán proporcionarse medidas de ayuda y asistencia específicas.

En ese tenor, ante la convencionalidad del derecho a través de los instrumentos internacionales como Tratados en los que México forma parte se debe preponderar el sistema normativo que valide el acceso a la justicia a las víctimas de DFI garantizando sus derechos humanos, atendiendo el estado de vulnerabilidad y riesgo, así como el estado de desatención.

\section{Derechos humanos. Interdependencia, indivisibilidad y progresividad.}

Las personas víctimas de DFI son titulares de los derechos civiles, políticos, económicos, sociales y culturales; toda vez que México considera en su artículo primero y ciento 
treinta y tres Constitucional los derechos humanos y los tratados internacionales respectivamente. Rousseau Jacques (2012), a través del contrato social caracteriza la voluntad general en concordancia con un bien común. La función del Estado en correspondencia con la propia ciudadanía debe procurar "el deber de prevenir" en sentido de tomar medidas de carácter jurídico, político, administrativo, civil, penal y cultural que promuevan los derechos humanos asegurando que las violaciones $u$ omisiones de los mismos sean tratadas como hechos ilícitos vinculantes a sanciones para quien comete el acto, así como la reparación a las víctimas por sus consecuencias perjudiciales como lo señala la CIDH (Comisión Interamericana de Derechos Humanos, 2015).

Respecto al "deber de investigar, procesar y sancionar" a nivel internacional la Corte IDH (Corte Interamericana de Derechos Humanos, 2011), ha referenciado el caso de la Familia Barrios vs Venezuela, en el que se señala la obligación de investigar seria, imparcial y efectiva las violaciones de derechos humanos previstas en las medidas positivas por parte del Estado. Manifiesta que no solamente se debe prevenir, sino que conlleva investigar y restablecer si es posible el derecho transgredido, en su caso, la reparación de daños.

Los grupos vulnerables no están exentos del DFI al respecto, Mercado (2016), integra en este grupo a mujeres, personas de edad, personas con discapacidad, las minorías, indígenas y otros grupos, también se debe comprender desde una perspectiva de género. Salazar (2014) expresa que el DFI es un acto de sobrevivencia en el que las personas están inseguras, vulnerables y sin protección; produciendo violaciones u omisiones de derechos humanos de forma interdependiente e indivisible.

En el DFI se puede distinguir los siguientes derechos vulnerados y/o violados:

- A la vida. - Referido de acuerdo a Naciones Unidas (1998), como protección en contra de genocidio; homicidio; ejecuciones sumarias o arbitrarias y desapariciones forzadas, secuestro, detención no reconocida con los elementos de amenaza o muerte.

- Dignidad. - Concerniente a la integridad física, mental y moral.

- Libertad. - Alusivo a toda independencia y en contra de violación, mutilación, tortura, penas o tratos crueles, inhumanos o degradantes u otros que atenten a su dignidad particular, violencia contra la mujer, prostitución forzada u otra forma que transgreda la libertada sexual. Se considera la esclavitud, trabajo de menores y actos violentos que diseminen terror y miedo a los desplazados, en ningún momento y bajo ninguna circunstancia serán considerados rehenes, por tal motivo Naciones Unidas (1998) puntualiza que tienen derecho a la libertad de circulación y de escoger su residencia.

- Seguridad. - Naciones Unidas (1998) lo puntualiza respecto a recibir protección contra el regreso forzado, reasentamiento donde se pueda encontrar en estado vulnerable 0 en riesgo. Tiene acceso a los mecanismos de protección desde lo local hasta en el sistema de justicia del marco internacional.

- Personalidad jurídica. - Las Naciones Unidas (1998), dispone que el estado mediante las autoridades competentes otorgará a las personas desplazadas todo documento necesario para el disfrute y ejercicio de sus derechos legítimos (pasaporte, documentos de identidad personal, partidas de nacimiento y certificados de matrimonio). Deberán tener facilidad a la documentación necesaria para el acceso a servicios públicos y bien material, de igual forma tiene derecho de ser votado y votar.

- Propiedad. Ninguna persona debe ser privada y limitada de su propiedad o posesiones bajo ningún motivo ni circunstancia. De acuerdo al "Caso de las comunidades afrodescendientes 
desplazadas de la cuenca del Río Cacarica (Operación Génesis) vs Colombia" (Corte Interamericana de Derechos Humanos, 2013), las personas desplazadas tienen el derecho, a que se les restituya los bienes de que se les privó durante el conflicto y a ser indemnizados debidamente por los bienes que no se les puede restituir.

- Educación. - Se debe asegurar de forma particular que los menores reciban educación gratuita y obligatoria a nivel primario respetando su identidad (cultural, idioma y religión), igualdad plena de la participación de mujeres y niñas. Es decir, este derecho se aboca a atender de forma gratuita en su nivel de competencia y recursos el acceso a la educación a niños, niñas, adolescentes y jóvenes.

- Derecho a la consulta y participación. Puntualizando que sea informada, aceptable, apropiada, sostenible e integral para la comunidad. Construcción de mecanismos en consenso con la o las víctimas y personas involucradas de forma directa.

- Derecho a la verdad. Las víctimas o familiares deben participar en todas las etapas de los procesos, que formulen pretensiones, presenten elementos probatorios, que de acuerdo a la Corte IDH (Corte Interamericana de Derechos Humanos, 2007), deben ser analizados completa y seriamente por las autoridades competentes antes de que se resuelva sobre hechos, responsabilidades, penas y reparaciones.

Por lo anterior, se trata entonces de un trabajo de comprensión y atención transversal, multidisciplinario, holístico, consensual e integral, que conozca y atienda de las necesidades reales de las personas en DFI acorde a su contexto.

México y la ausencia de programación presupuestal en el desplazamiento forzado interno.

La Secretaría de Hacienda y Crédito Público-SHCP (2019), en su Estructura Programática a emplear en el proyecto de Presupuesto de Egresos 2020, tiene contemplado ejercer el presupuesto en temas específicos de la Movilidad Humana solamente en Refugiados y Migrantes.

En la programación presupuestal se haya el rubro "Refugiados en el ramo/sector Administrativo "Gobernación" en la modalidad del programa "Atención a refugiados en el país".

En el caso de Migrantes, en el ramo/sector Administrativo "Bienestar" a través del "Programa 3x1 para Migrantes". En el ramo/sector "Provisiones salariales y económicas" el criterio U033 "Fondo de Apoyo a Migrantes" con la finalidad de promover acciones de desarrollo regional. En el Ramo/sector Autónomo "Comisión Nacional de los Derechos Humanos" E003 "Atender asuntos relacionados con las personas migrantes" como actividad institucional "Protección y Defensa de los Derechos Humanos".

Los datos anteriores solamente indican que, a través de la Secretaria de Gobernación, Secretaria de Educación y la Comisión de Derechos Humanos, se asigna un presupuesto en atención a migrantes y refugiados, en ningún momento se consideran a las víctimas de DFI.

En esa misma estructura programática, han existido modificaciones en atención al tema de los Migrantes, por mencionar; escisión del criterio "Pp S244 Programa para la Inclusión y la Equidad Educativa", que desaparece para 2020 y a partir del cual se crea el rubro denominado "S297 Atención Educativa de la Población Escolar Migrante (PAEPEM)", es decir, se aboca a crear un programa educativo específico para el sector migrante derivado de la complejidad para abordar las diferentes problemáticas, poblaciones, apoyos y mecanismos de 
operación de los niveles educativos y modalidades (educación especial, educación indígena, educación migrante y estudiantes en contexto de vulnerabilidad en educación media superior).

Respecto a las erogaciones para el desarrollo integral de los pueblos y comunidades indígenas, conforme a la Secretaría de Hacienda y Crédito Público (2019), se presupone lo siguiente: en el ramo 20 de Bienestar "Programa 3x1 para Migrantes" se destinó 15, 788, 640 millones de pesos. En el caso de acciones para la prevención del delito, combate a las adicciones, rescate de espacios públicos y promoción de proyectos productivos, se considera al ramo Administrativo de Bienestar "Programa 3x1 para Migrantes" con la cantidad de 60,666,269 millones de pesos; en ese mismo programa del ramo 20 "Bienestar" se ha considerado una ampliación S061 por un monto total de 200,000,000 millones de pesos.

Aun cuando ya se describió en líneas anteriores que el DFI representa a nivel mundial y nacional un problema complejo y que México está trabajando en la creación de Ley; en la asignación presupuestal del año 2020 en tema de Movilidad Humana no hay un recurso para esta problemática. Es importante mencionar que al traspasar los límites dentro y en las propias entidades federativas como característica de este fenómeno $\mathrm{DFI}$, se requiere de una atención e intervención a nivel federal, ya que se puede señalar que los estados de Guerrero y Chiapas, de forma estatal tratan de abordar este fenómeno a través de Fondos destinados que, si bien no son específicos, los DFI si están considerados en el aspecto de movilidad humana.

La creación de la Ley DFI conlleva el interés de proporcionar una base sólida para la planificación y priorización de actividades en apoyo a personas, familias y comunidades víctimas de este fenómeno, además de la asignación apropiada de recursos (Secretaría de GobernaciónSEGOB, 2019). Un eje trascendental para el análisis es que las personas en DFI no son ajenas a la jurisdicción del estado mexicano, en ningún momento pierden derechos ya reconocidos por el propio Estado, esto acontece debido a que en las circunstancias en las que se encuentran las personas, es carente de una marco legal e institucional y, por lo tanto, también de un conocimiento profesional del tema por parte de las propias autoridades.

Parte de ese escenario complejo, se ha identificado el origen del DFI en México por regiones; en los estados fronterizos del norte es causado por el narcotráfico ya sea crimen organizado concerniente a disputa de territorios, distribución y el tráfico de droga, que desata secuestro, lavado de dinero, asaltos con violencia, asesinatos, tráfico de órganos y corrupción policial. En el caso de la región Centro es suscitado por motivos de pérdida patrimonial, secuestro e intento de secuestro, robo a casa habitación, asalto a mano armada, robo de vehículo, extorsión telefónica a negocio, fraude, cobro por protección, lavado de dinero, crimen organizado. En la región del sur de acuerdo a la Secretaría de Gobernación en conjunto con el Consejo Nacional de Población-CONAPO (SEGOB-CONAPO, 2019), los motivos son por amenazas de muerte, despojo de bienes comunales, conflictos religiosos y políticos, intentos de construir municipios autónomos.

Al respecto, se considera importante, crear acciones de políticas públicas (Mercado, 2018), encaminadas a la inversión científica a través de investigaciones disciplinares, transversales que puedan determinar causas, alcance, factores, dinámica del DFI, además de distinguir e identificar el perfil de la víctima, esto como medida de conocer, tener un diagnóstico y trabajar en ello de acuerdo a las necesidades de la realidad del contexto.

Es trascendental considerar llevar a efecto la matriz de seguimiento de movilidad humana, siendo una opción adoptar la que otorga la Organización Internacional para las Migraciones (2004), instrumento creado para el seguimiento y la vigilancia de los 
desplazamientos y la determinación de los lugares donde se instalan los desplazados internos, mismo que aporta datos reales empíricos que coadyuvan al sistema del Estado para identificar las causales y atender las necesidades pronosticando y contextualizando sus tendencias, patrones e impactos.

El gobierno debe abordar sustancialmente el tema, teniendo un diagnóstico y poder programar en el presupuesto acciones concretas en el tema a través de políticas públicas (Serrano y Vázquez, 2013), así como dimensionar los costos e impactos que se originan por el DFI.

Por último, este apartado denota la ausencia de fondos que atiendan el DFI y por tanto hay carencia de políticas públicas que lo coadyuven. Se plantea que como mecanismo de atención u obtención de financiamiento para diagnóstico 0 atención de forma integral se colabore en la participación académica y de investigación con fondos económicos que ofrece por concurso el Consejo Nacional de Ciencia y Tecnología-CONACYT.

Otra perspectiva de abordar o transformar este problema social es con la inclusión y reconocimiento de derechos de las personas, tal como el derecho al trabajo, puede implicar la ejecución de diferentes actividades que las autoridades estatales pueden realizar en favor de las víctimas de DFI. Por ejemplo, recursos para la ejecución de proyectos, programas de microcréditos, programas de formación profesional y de formación técnica y cualquiera que ayude a las personas desplazadas a generar ingresos para su mantenimiento personal y familiar, en tanto puedan retornar a sus lugares de origen en condiciones de seguridad o reasentarse de manera permanente en alguna otra comunidad, de acuerdo a como los describe la Recomendación No. 94 (Comisión Nacional de Derechos Humanos, 2019). Asimismo, algún tipo de beneficio fiscal a empresas que contraten a personas desplazadas o que generen un beneficio para la comunidad.

Finalmente, al reconocer como víctima a toda persona en estado de DFI se debe tener como efecto que acceda a un fondo de reparación integral del daño.

\section{Conclusión}

La movilidad humana manifestada mediante el DFI confronta una problemática social la cual, por su trascendencia e impacto local en un país, debe considerar mecanismos de atención que prevean, atiendan y protejan actos u omisiones que vulneren, transgredan o violen los derechos de las personas desplazadas.

En lo relativo al marco legal, siendo susceptibles las garantías por parte del Estado en el acceso de los derechos fundamentales, derechos humanos y derechos humanitarios internacional de las víctimas, se carece de marco legal específico, instancias, infraestructura y personal profesional dirigido a atender las necesidades de las víctimas para coadyuvar el marco institucional existente, así como la protección y asistencia por parte del Estado y órganos competentes. En caso contrario, al no existir un marco legal específico, el sistema de acceso de justicia y garantía del mismo es susceptible a una serie de inconsistencias en su aplicabilidad. Los derechos humanos son entonces vulnerados, violados $u$ omitidos por las autoridades y ciudadanía. El conocimiento y uso benéfico de los mismos permite su satisfacción en todo momento a través de una real progresividad.

En lo pertinente al presupuesto y programación el gobierno federal y estatal, debe considerar que el DFI es un escenario previo a situaciones de refugiados o migración a escala 
internacional. Por lo tanto, como distan Besana, et al (2020), debe mirarse a acciones de escala local, es decir, abordar este tipo de temas emergentes y contemplarlo en el ejercicio presupuestal, con el fin de afianzar un sistema de prevención, asistencia integral, protección a víctimas, recuperación de zonas afectadas, reinserción y atención de las personas desplazadas.

\section{Referencias Bibliográficas}

ACNUR. (1994). Declaración de San José sobre Refugiados y Personas Desplazadas y los Principios Rectores de los Desplazamientos Internos. ACNUR. Costa Rica.

Alto Comisionado de las Naciones Unidas para los Refugiados. (1984). Declaración de Cartagena sobre Refugiados, adoptado por el "Coloquio Sobre la Protección Internacional de los Refugiados en América Central, México y Panamá: Problemas Jurídicos y Humanitarios". ACNUR. Colombia.

Asamblea Legislativa del Distrito Federal V Legislatura. (2011). Ley de Interculturalidad, atención a Migrantes y Movilidad Humana en el Distrito Federal. México.

Besana, Patricio; Fernández, Soledad; Monserrat, Ana. (2020). Lo que el viento se llevó: No participación local en un conflicto sobre un ambiente de dunas. Revista TELOS. Volumen 22, No. 1, Venezuela. (Pp.6-30). DOI: www.doi.org/10.36390/telos221.02

Cámara de Diputados del H. Congreso de la Unión. (1917). Constitución Política de los Estados Unidos Mexicanos, Constitución publicada en el Diario Oficial de la Federación el 5 de febrero de 1917. Última Reforma Publicada DOF 08-05-2020. México.

Cámara de Diputados del H. Congreso de la Unión. (1974). Ley General de Población. Nueva Ley publicada en el Diario Oficial de la Federación el 7 de enero de 1974. Última reforma publicada DOF 12-07-2018. México.

Cámara de Diputados del H. Congreso de la Unión. (2011a). Ley de Migración. Nueva Ley publicada en el Diario Oficial de la Federación el 25 de mayo de 2011. Última reforma publicada DOF 13-04-2020. México.

Cámara de Diputados del H. Congreso de la Unión. (2011b). Ley sobre Refugiados, Protección Complementaria y Asilo Político Nueva Ley publicada en el Diario Oficial de la Federación el 27 de enero de 2011. Última reforma publicada DOF 30-10-2014. México.

Cámara de Diputados del H. Congreso de la Unión. (2013). Ley General de Víctimas. Nueva Ley publicada en el Diario Oficial de la Federación el 9 de enero de 2013. Última Reforma Publicada DOF 03-01-2017. México.

Cámara de Diputados del H. Congreso de la Unión. (2004). Ley de Asistencia Social. Nueva Ley publicada en el Diario Oficial de la Federación el 2 de septiembre de 2004. Última Reforma Publicada DOF 24-04-2018. México.

Cámara de Diputados del H. Congreso de la Unión. (2019). Ley General de Educación. Nueva Ley publicada en el Diario Oficial de la Federación el 30 de septiembre de 2019. México.

CIREFCA. (1989). Conferencia Internacional sobre Refugiados Centroamericanos, Principios y criterios para la protección y asistencia a los refugiados, repatriados y desplazados Centroamericanos en América Latina. CIREFCA. Guatemala.

Comisión Interamericana de Derechos Humanos. (2015). Movilidad Humana. Estándares interamericanos. Derechos humanos de migrantes, refugiados, apátridas, víctimas 
de trata de personas y desplazados internos: normas y estándares del Sistema Interamericano de Derechos Humanos. OEA. España.

Comisión Nacional de Derechos Humanos. (2019). Recomendación No. 94 /2019. CNDH. México.

Comisión Nacional de Derechos Humanos. (2016). Informe especial sobre el Desplazamiento Forzado interno (DFI) en México. CNDH. México.

Comisión Mexicana de Defensa y Promoción de los Derechos Humanos. (2019). Desplazamiento interno forzado en México. Comisión Mexicana de Defensa y Promoción de los Derechos Humanos. CMDPDH. México.

Comité Internacional de la Cruz Roja. (1949). Convenios de Ginebra. CICR. Suiza.

Congreso del Estado Libre y Soberano de Chiapas. (2012). Congreso del Estado Libre y Soberano de Chiapas. México.

Corte Interamericana de Derechos Humanos. (2013). Caso de las comunidades afrodescendientes desplazadas de la cuenca del Río Cacarica (Operación Génesis) vs Colombia. Corte IDH. Colombia.

Corte Interamericana de Derechos Humanos. (2011). Caso Familia Barrios Vs. Venezuela. Fondo, Reparaciones y Costas. Sentencia de 24 de noviembre de 2011. Corte IDH. Costa Rica.

Corte Interamericana de Derechos Humanos. (2007). Caso de la Masacre de la Rochela Vs. Colombia. Fondo, Reparaciones y Costas. Sentencia de 11 de mayo de 2007. Corte IDH. Costa Rica.

Garza, Ario. (2013). Manual de técnicas de investigación para estudiantes

de

Ciencias Sociales y Humanidades. Editorial COLMEX. México.

H. Congreso del Estado. (2013a). Ley de atención y reparación a víctimas del delito y de violaciones a los derechos humanos para el estado de Morelos. Última Reforma 2014. México.

H. Congreso del Estado. (2013b). Ley de Víctimas del estado de Morelos. Última Reforma 2019. México.

H. Congreso Local. (2014). Ley número 487 para prevenir y atender el desplazamiento interno en el estado de Guerrero. México.

Luhmann, Niklas. (2006). Sociología del riesgo. Editorial Universidad Iberoamericana. México. Mercado, Jorge. (2016). El desplazamiento interno forzado en México, El cotidiano, $\mathrm{N}^{\circ} 200$, noviembre-diciembre, México (Pp. 181-192).

Mercado, Jorge. (2018). Pueblos indios y desplazamiento interno forzado. El camino recorrido para el establecimiento de una ley para el estado de Chiapas. Revista de Ciencias Antropológicas, Volumen 25, No. 73, México, (Pp. 133-163).

Mestries, Francis. (2018). Políticas públicas y derechos de los desplazados internos forzados. Cuicuilco. Revista de Ciencias Antropológicas, Volumen 25, No. 73, México, (Pp. 99-131).

Naciones Unidas. (1948). Declaración Universal de los Derechos Humanos, Comisión de Derechos Humanos. Francia.

Naciones Unidas. (1998). Principios rectores de los desplazamientos internos, Consejo Económico y Social. Comisión de Derechos Humanos. Estados Unidos. 
Naciones Unidas. (2016). Informe del Relator Especial sobre los derechos humanos de los desplazados internos. Consejo de Derechos Humanos. Estados Unidos.

Observatorio de Desplazamiento Interno-IDMC. (2019). Informe Mundial sobre Desplazamiento Interno 2019. IDMC. Suiza.

Organización de los Estados Americanos-OEA. (1948). Declaración Americana de los Derechos y Deberes del Hombre. OEA. Colombia.

Organización Internacional del Trabajo-OIT. (1989). Convenio 169 sobre pueblos indígenas y tribales en países independientes. OIT. Suiza.

Organización Internacional para las Migraciones. (2004). Matriz de seguimiento de movilidad humana. OIM-ONU-Migración. Suiza.

Pérez Vázquez, Brenda Gabriela, Bachi Morales, Daniela, de Aquino Barbosa Magalhaes, Castillo Portillo, Montserrat. (2019). Informe Episodios de Desplazamiento Interno Forzado Masivo en México 2018. Comisión Mexicana de Defensa y Promoción de los Derechos Humanos. México.

Rousseau Jacques, Jean. (2012). El contrato social. Editorial Edaf. España.

Salazar, Luz María. (2014). Modalidades del desplazamiento interno forzado en México. Iztapalapa. Revista de ciencias sociales y humanidades, Volumen 35 , No. 76 , México, (Pp. 53-81).

Salazar, Luz María y Álvarez, José Antonio. (2018). Violencia y desplazamientos forzados en México. Revista de Ciencias Antropológicas, No. 73, septiembre-diciembre, México, (Pp. 19-37).

Serrano, Sandra y Vázquez, Daniel. (2013). Los derechos en acción. Obligaciones y principios de derechos humanos. Editorial FLACSO. México.

SEGOB-CONAPO. (2019). Focaliza gobierno de México acciones para detectar, prevenir y atender el desplazamiento forzado interno. Secretaría de Gobernación. Comunicado con fecha de 25 de julio de 2019. México.

Secretaría de Hacienda y Crédito Público. (2019). Programática a emplear en el proyecto de Presupuesto de Egresos 2020. SHCP. México.

Unión Africana. (2009). Convención de la Unión Africana para la protección y la asistencia de los desplazados internos en África (Convención de Kampala). ACNUR, Uganda.

Villabella, Carlos Manuel (2009). La investigación científica en la ciencia jurídica. Sus particularidades. IUS. Revista del Instituto de Ciencias Jurídicas de Puebla A.C., No. 23, México. (Pp. 5-37). 